\title{
E3 ubiquitin ligase-mediated regulation of bone formation and tumorigenesis
}

\author{
N Sévère ${ }^{1,2}$, F-X Dieudonné ${ }^{1,2}$ and PJ Marie ${ }^{*, 1,2}$
}

The ubiquitination-proteasome and degradation system is an essential process that regulates protein homeostasis. This system is involved in the regulation of cell proliferation, differentiation and survival, and dysregulations in this system lead to pathologies including cancers. The ubiquitination system is an enzymatic cascade that mediates the marking of target proteins by an ubiquitin label and thereby directs their degradation through the proteasome pathway. The ubiquitination of proteins occurs through a three-step process involving ubiquitin activation by the E1 enzyme, allowing for the transfer to a ubiquitin-conjugated enzyme E2 and to the targeted protein via ubiquitin-protein ligases (E3), the most abundant group of enzymes involved in ubiquitination. Significant advances have been made in our understanding of the role of E3 ubiquitin ligases in the control of bone turnover and tumorigenesis. These ligases are implicated in the regulation of bone cells through the degradation of receptor tyrosine kinases, signaling molecules and transcription factors. Initial studies showed that the E3 ubiquitin ligase c-Cbl, a multi-domain scaffold protein, regulates bone resorption by interacting with several molecules in osteoclasts. Further studies showed that $\mathrm{c}-\mathrm{Cbl}$ controls the ubiquitination of signaling molecules in osteoblasts and in turn regulates osteoblast proliferation, differentiation and survival. Recent data indicate that $\mathrm{c}-\mathrm{Cbl}$ expression is decreased in primary bone tumors, resulting in excessive receptor tyrosine kinase signaling. Consistently, $\mathrm{c}$-Cbl ectopic expression reduces bone tumorigenesis by promoting tyrosine kinase receptor degradation. Here, we review the mechanisms of action of E3 ubiquitin ligases in the regulation of normal and pathologic bone formation, and we discuss how targeting the interactions of $\mathrm{c}-\mathrm{Cbl}$ with some substrates may be a potential therapeutic strategy to promote osteogenesis and to reduce tumorigenesis.

Cell Death and Disease (2013) 4, e463; doi:10.1038/cddis.2012.217; published online 17 January 2013

Subject Category: Cancer

Facts

- E3 ubiquitin ligases are important proteins regulating bone turnover.

- The E3 ubiquitin ligases c-Cbl and Cbl-b interact with RTKs and other molecules to control bone cell proliferation, differentiation and survival.

- Inhibition of $\mathrm{c}-\mathrm{Cbl}$ promotes osteoblast differentiation through decreased RTK degradation.

- c-Cbl expression is decreased in bone tumors and is a tumor suppressor in osteosarcoma.

- c-Cbl ectopic expression decreases RTK levels and reduces bone tumor growth and metastasis by inhibiting cell proliferation, migration and invasion.

\section{Open Questions}

- Identification of molecules interacting with $\mathrm{c}-\mathrm{Cbl}$ that could be targeted to selectively promote osteogenesis in vivo.

- Determination of $\mathrm{c}-\mathrm{Cbl}$ expression in relation to diagnosis and prognosis in solid tumors.

- Development of efficient and nontoxic tools targeting the interactions between c-Cbl and its specific substrates for a potential therapeutic use in bone disorders and cancers.

The ubiquitin-dependent proteolysis system (UPS) mediating protein degradation is an essential process involved in the

\footnotetext{
${ }^{1}$ Laboratory of Osteoblast Biology and Pathology, INSERM U606, Paris, 75475, France and ${ }^{2}$ University Paris Diderot, Sorbonne Paris Cité, Paris, 75475, France ${ }^{*}$ Corresponding author: PJ Marie, INSERM U606, Hôpital Lariboisière, 2 rue Ambroise Paré, Paris Cedex 10, 75475 France. Tel: +33 149956389 ; Fax: + 331499584 52; E-mail: pierre.marie@ inserm.fr

Keywords: ubiquitin ligases; proteasome; receptor tyrosine kinases; bone tumors; Cbl proteins; ubiquitination

Abbreviations: RTK, receptor tyrosine kinase; UPS, ubiquitin-dependent proteolysis system; TKB, tyrosine kinase binding domain; UBA, ubiquitin-associated domain; MSC, mesenchymal stromal cells; Bzb, Bortezomib; BMP, bone morphogenetic protein; PTH, parathyroid hormone; IGFR, insulin-like growth factor receptor; IRS-1, insulin receptor substrate-1; FGFR, fibroblast growth factor receptor; EGFR, epidermal growth factor receptor; PDGFR, platelet growth factor receptor; TGF- $\beta 1$, transforming growth factor- $\beta 1$; DUB, deubiquitinase; HECT, homologous to E6AP carboxyl terminus; GSK-3 $\beta$, glycogen synthase kinase-3 $\beta$; DKK1, Dickkopf1; Smurf1, Smad ubiquitination regulatory factor 1; TNF- $\alpha$, tumor necrosis factor- $\alpha$; Plekho1, caseine-kinase 2 interacting protein-1; ATF4, activating transcription factor 4; PI3K, phosphatidylinositol-3' kinase; c-Fms, M-CSF receptor; RANK, receptor activator of NF- $\kappa$ B.

Received 8.10.12; revised 7.12.12; accepted 17.12.12; Edited by H-U Simon
} 
regulation of cell proliferation, differentiation and apoptosis. The ubiquitination process consists in adding ubiquitin chains on target proteins, which leads to mono- or polyubiquitination of the protein that is then degraded by the proteasome. ${ }^{1}$ The ubiquitination cascade requires the successive action of three enzymes. The first enzyme (E1) involved in the ubiquitination process is the ubiquitin-activating enzyme recruiting ubiquitin. The second enzyme (E2) is the ubiquitin-conjugating enzyme that transfers the ubiquitin to the targeted protein. The third enzyme (E3) is the ubiquitin ligase acting as a scaffold protein that interacts with the E2 enzyme and transfers ubiquitin to the target protein. ${ }^{2,3}$ This process is reversible through the action of deubiquitinases (DUBs) that remove ubiquitin chains linked to the target protein. ${ }^{4}$ More than 600 E3 ubiquitin ligases are expressed in the human genome, allowing for the specificity of the ubiquitination system. ${ }^{5}$ Based on their distinct function, E3 ubiquitin ligases have been classified as homologous to E6AP carboxyl terminus (HECT)-type and RING-finger like proteins. E3 ubiquitin ligases play a key role in cellular functions by determining the specificity for degradation of substrates, marking it for degradation by the proteasome or the lysosome. ${ }^{6}$ However, ubiquitination of a given protein does not necessarily lead to its degradation as ubiquitin may control other biological processes including DNA repair, endocytosis, autophagy, transcription, immunity and inflammation. ${ }^{7}$ Interestingly, E3 ligases are themselves regulated by ubiquitination and targeted for degradation, which makes the protein recognition system self-regulated..$^{8}$

During the recent years, it became apparent that E3 ubiquitin ligases regulate various cellular processes involved in the control of bone turnover. Initial studies showed that the Cbl family of E3 ubiquitin ligases regulates bone resorption by osteoclasts. Recent studies indicate that c-Cbl also plays a role in the control of osteogenesis and bone tumorigenesis. Here, we summarize the roles of the Cbl family of E3 ubiquitin ligases in the ubiquitination of specific proteins that control bone-forming cells and tumorigenesis, and we review the implications of this knowledge for controlling bone formation in normal and pathological conditions.

\section{The Ubiquitination and Degradation System and Bone Turnover}

The skeleton is continuously renewed by bone remodeling that starts by the resorption of the bone matrix by osteoclasts, ${ }^{9}$ followed by the formation of a new bone matrix by osteoblasts. ${ }^{10}$ The early differentiation of osteoblasts is mainly controlled by the transcriptional factor Runx2, followed by the expression of osteoblast phenotypic genes and the synthesis of a bone matrix. ${ }^{11,12}$ At the end of the bone formation period, osteoblasts become flattened lining cells, are embedded into the bone matrix as osteocytes or die by apoptosis. ${ }^{13}$ All these stages are regulated by several transcription factors, hormones, growth factors and the extracellular matrix, most of them acting by regulating Runx2 gene expression or activity. ${ }^{12,14,15}$

In the recent years, significant advances have been made in our understanding of the role of UPS in regulating bone cell functions. Initial studies using proteasome inhibitors demonstrated that the ubiquitination-degradation system is an important mechanism controlling bone turnover. ${ }^{16,17}$ Notably, inhibition of the proteasome leads to increased bone formation and to recovery of bone loss induced by ovariectomy in mice. ${ }^{18}$ Consistent with these findings, clinical studies showed that the proteasome inhibitor Bortezomib (Bzb) promotes osteoblastogenesis and inhibits bone resorption in patients with multiple myeloma. ${ }^{19-21}$ These effects are mediated by the inhibition of degradation of proteins controlling bone formation and resorption. ${ }^{22}$ One of the identified proteins is $\beta$-catenin that plays an essential role in chondrogenesis ${ }^{23}$ and bone cell function. ${ }^{24}$ Wnt binding to Wnt coreceptors LRP5 and Frizzled leads to the inhibition of glycogen synthase kinase-3 $\beta$ (GSK-3 $\beta$ ), leading to decreased $\beta$-catenin phosphorylation and prevention of its proteasomal degradation. ${ }^{25}$ In chondrocytes, Bzb increases $\beta$-catenin (a negative regulator of chondrogenesis) and thereby causes cell apoptosis and growth retardation in mice. ${ }^{16,26}$ In osteoblasts, $\beta$-catenin accumulation induced by proteasome inhibition leads to increased osteoblastic cell proliferation,

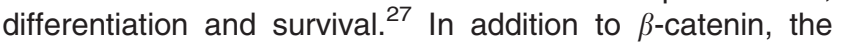
Bzb-induced bone formation is mediated by reduced degradation of Dickkopf1 (Dkk1), an extracellular Wnt/ $\beta$-catenin antagonist. $^{20}$ Another mechanism that is targeted by the proteasome is Hedgehog signaling. Specifically, proteasome inhibition decreases the degradation of the zinc-finger transcription factor Gli2 that mediates bone morphogenetic protein-2 (BMP2) expression in response to Hedgehog signaling, resulting in increased bone formation. ${ }^{28,29}$ Thus, several proteins can be targeted by proteasome inhibitors in osteoblasts, resulting in increased osteoblastogenesis and bone formation. In addition to its effect on osteoblasts, the inhibition of the proteasome has an important impact on bone resorption. Notably, proteasome inhibitors suppress osteoclastogenesis and decrease bone resorption mainly by acting on the NF- $\kappa \mathrm{B}$ signaling pathway, causing a reduction in the expression of receptor activator of $N F-\kappa B$ ligand (RANKL), which is essential for osteoclastogenesis. ${ }^{30-32}$ Overall, these studies provided evidence that the UPS is highly implicated in the regulation of bone turnover by affecting the degradation of several proteins regulating bone cell metabolism.

\section{Role of E3 Ubiquitin Ligases in Bone-Forming Cells}

E3 ubiquitin ligases play an important role in bone through their implication in directing proteins to proteasomal degradation. Smad ubiquitination regulatory factor 1 (Smurf1) is the first HECT domain ubiquitin ligase that was shown to regulate bone formation. Mechanistically, Smurf1 associates with the transcription factor Runx2 and mediates its degradation in ubiquitin- and proteasome-dependent manner, resulting in inhibition of osteoblast differentiation and bone formation. ${ }^{33-35}$ Consistently, Smurf1 expression induced by tumor necrosis factor- $\alpha$ (TNF- $\alpha$ ) results in Runx2 degradation. ${ }^{36,37}$ In contrast, inhibition of Smurf1 leads to increased Runx2 protein levels and increased osteoblast differentiation of mesenchymal cells, resulting in enhanced bone formation in vivo. $^{38}$ The anabolic factor BMP2 stimulates Runx2 acetylation and thereby prevents Smurf1-induced Runx2 degradation. ${ }^{39}$ In addition to regulating Runx2 degradation, Smurf1 mediates the degradation of Smad1, a downstream 
mediator of BMP receptors, and thereby inhibits BMP-induced osteoblast differentiation. ${ }^{33}$ Consistently, inhibition of Smurf1mediated Smad1 degradation results in activation of osteoblast differentiation. ${ }^{40}$ It was recently shown that silencing of the gene encoding caseine-kinase 2 interacting protein-1 (Plekho1), a cofactor for Smurf1, leads to enhanced osteoblast differentiation, bone formation and bone mass in osteopenic rats, which supports an important role of Smurf1 in osteogenesis. ${ }^{41}$ Smurf1 also mediates some effects of parathyroid hormone (PTH) in bone-forming cells. Continuous PTH treatment increases Smurf1 expression, leading to Runx2 degradation and attenuation of anti-apoptotic signaling in osteoblasts. ${ }^{42}$ In addition to the control of Runx2 degradation, Smurf1 negatively regulates osteoblast differentiation by increasing JunB and MEKK2 degradation through the ubiquitin-proteasome pathway. ${ }^{33,35,43}$ All these studies illustrate how the E3 ubiquitin ligases Smurf1 negatively regulate osteogenesis (Figure 1).

Other E3 ubiquitin ligases were shown to play important roles in osteogenesis. The transcription factor Runx2 is controlled by the E3 ubiquitin ligase CHIP that promotes Runx2 degradation in preosteoblasts, resulting in inhibition of osteoblast differentiation. ${ }^{44}$ Another E3 ubiquitin ligase, Wwp1, interacts with Runx2 and the zinc-finger adapter protein Schnurri-3, resulting in increased Runx2 polyubiquitination and proteasome degradation. Consistently, Schnurri3 deficiency in mice increases osteoblast gene expression and osteoblast activity, ${ }^{45}$ and Wwp1 deletion in mice leads to increased Runx2 and bone mass. ${ }^{45}$ Wwp1 also promotes the ubiquitination and degradation of JunB, an AP-1 transcription factor that positively regulates osteoblast differentiation. The role of Wwp1 in osteogenesis was demonstrated in Wwp1 knockout mice that do not exhibit the TNF- $\alpha$-induced JunB ubiquitination and subsequent inhibition of osteoblast differentiation observed in wild-type mice. ${ }^{46}$ On the other hand, intermittent PTH treatment was found to increase activating transcription factor 4 (ATF4) protein level as a result of decreased proteasomal degradation by the E3 ubiquitin ligase $\beta$-TrCP1, resulting in increased osteoblastogenesis. ${ }^{47}$ Finally, overexpression of the E3 ligase complex SCF that regulates the ubiquitination and degradation of p57 (KIP2) induced by transforming growth factor- $\beta 1$ (TGF- $\beta 1$ ) inhibits osteogenic differentiation, whereas the expression of a dominant-negative form of SCF promotes osteogenic differentiation. ${ }^{48}$ Overall, these studies emphasize the important roles of these specific E3 ubiquitin ligases and UPS in the control of bone-forming cells and bone formation (Figure 1).

\section{The E3 Ubiquitin Ligase Cbl Protein Family}

The Cbl proteins are RING domain-type E3 ubiquitin ligases that are important regulators of signal transduction and cell functions. ${ }^{49-51}$ The first member of $\mathrm{Cbl}$ family, v-Cbl, is a truncated form of the wild-type form $\mathrm{c}-\mathrm{Cbl}$ that was isolated from a retrovirus Cas NS-1 that induces lymphoma in mice. Since then, three isoforms of $c-C b l$ have been described in mammals (c-Cbl, Cbl-b and Cbl-3), two in drosophilia (d-Cbl $\mathrm{d}-\mathrm{Cb}_{\mathrm{L}}$ ), and one in Caenorhabditis elegans (Sli-1). ${ }^{52} \mathrm{Cbl}$ proteins are scaffold proteins with multiple interaction domains $^{53,54}$ (Figure 2a). Two domains, the tyrosine kinase

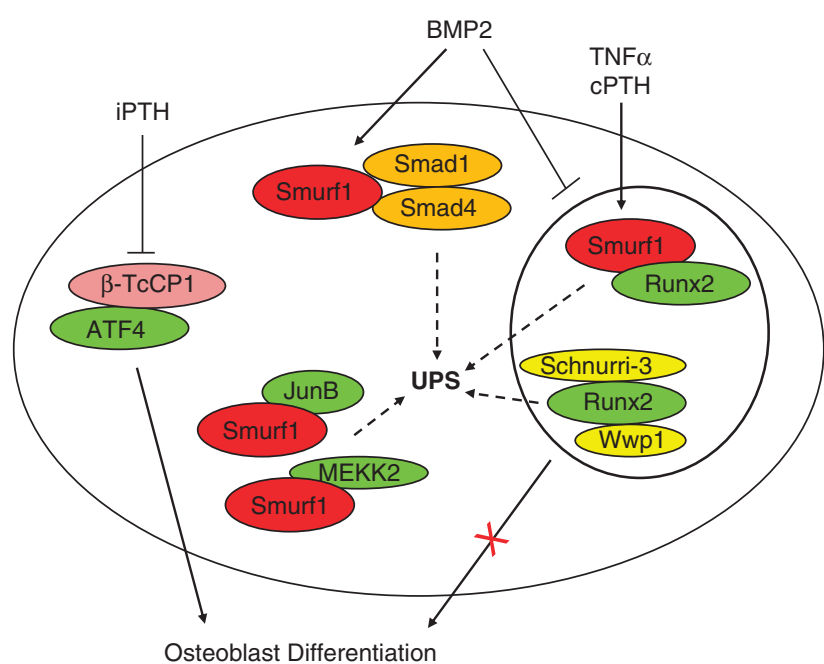

Figure 1 E3 ubiquitin ligases controlling bone-forming cells. The E3 ubiquitin ligase Smurf1 mediates the ubiquitination and degradation of the main osteoblast transcription factor Runx2, as well as the signaling proteins JunB, MEKK2 and BMP2-activated Smad1 and Smad4. Runx2 degradation is mediated by Wwp1 and Schnurri-3, resulting in decreased osteoblast differentiation and bone formation. The anabolic factor BMP2 stimulates Runx2 acetylation and thereby prevents Smurf1-induced Runx2 degradation. The catabolic factor TNF- $\alpha$ enhances Smurf1 expression that results in Runx2 degradation. Continuous PTH (cPTH) increases Smurf1 expression whereas intermittent PTH (iPTH) prevents ATF4 degradation by $\beta$-TcCP1, thereby promoting bone formation

binding domain (TKB) and the RING (really interesting new gene) domain, are highly conserved. The TKB domain is essential for the interaction of Cbl proteins with phosphorylated tyrosine-containing peptides. The RING domain controls the ubiquitin ligase activity of $\mathrm{Cbl}$ proteins by binding to the $\mathrm{E} 2$ ubiquitin-conjugating enzymes. ${ }^{53}$ Sprouty interacts with the RING domain of $\mathrm{Cbl}$ proteins and thereby sequesters $\mathrm{Cbl}$ away from activated RTKs. ${ }^{55}$ The linker domain bearing two important tyrosines ( $\mathrm{Tyr}^{368}$ and $\mathrm{Tyr}^{371}$ ) is an important link between the TKB and the RING domains. ${ }^{56}$ Notably, Tyr ${ }^{371}$ phosphorylation activates $\mathrm{Cbl}$ by inducing conformational changes that eliminate autoinhibition. ${ }^{57,58}$ The C-terminal part is much less conserved among $\mathrm{Cbl}$ proteins. The proline-rich domain interacts with $\mathrm{SH} 3$ domain proteins of Src and Grb2. The ubiquitin-associated domain (UBA) is an interacting domain that interacts noncovalently with (mono) ubiquitin or preferentially with polyubiquitinated chains. ${ }^{3}$ The most abundant $\mathrm{Cbl}$ proteins in bone, $\mathrm{Cbl}$ and $\mathrm{Cbl}-\mathrm{b},{ }^{59}$ share sequence similarity in the N-terminal half, including the TKB domain that binds phosphorylated tyrosine residues, the linker domain and the RING domain that binds the E2 ubiquitin-conjugating enzymes. However, the two Cbl proteins exhibit structural differences in the $\mathrm{C}$-terminal parts such as the presence of $\mathrm{Y}^{731}$ in c-Cbl that acts as a docking site for the Src homology 2 (SH2) domain of the p85 subunit of phosphorylated phosphatidylinositol-3' kinase (PI3K), and sequence differences in the UBA domains that differ in their ability to bind polyubiquitin chains and ubiquitylated proteins. ${ }^{60,61}$ Because of these multiple domains, $\mathrm{Cbl}$ proteins can interact with a large number of proteins. ${ }^{51,59,62-64}$ Most importantly, Cbl proteins act as negative regulators of growth factor receptors and 
nonreceptor tyrosine kinases that play essential roles in normal and pathological bone cell functions.

\section{Role of Cbl E3 Ubiquitin Ligases in Bone Resorption}

Deletion of both $\mathrm{c}-\mathrm{Cbl}$ and $\mathrm{Cbl}-\mathrm{b}$ genes induces early embryonic lethality, indicating that the two proteins play essential roles during development. ${ }^{65}$ Both $c-C b l$ and Cbl-b are expressed by osteoclasts ${ }^{66}$ in association with podosomes $^{67}$ that are required for normal osteoclast migration and resorption activity. $\mathrm{c}-\mathrm{Cbl}$ regulates the actin cytoskeleton and stabilizes microtubules ${ }^{68}$ that are important for osteoclast activity. The extinction of Cbl-b increases osteoclast activity and induces bone loss in mice, ${ }^{69}$ whereas deletion of $\mathrm{c}-\mathrm{Cbl}$ reduces osteoclast migration and bone resorption during development. ${ }^{66}$ The opposite effects of these two Cbl proteins on osteoclast differentiation, function and survival are likely related to their interactions with distinct proteins in osteoclasts. ${ }^{69-71}$ Specifically, the structural differences that could account for the different bone phenotypes of c-Cbl- and Cbl-bdeficient mice include phosphorylation of $\mathrm{Tyr}^{731}$, a binding site for $\mathrm{PI} 3 \mathrm{~K}$, in $\mathrm{Cbl}$ but not in $\mathrm{Cbl-} b,{ }^{60}$ and the different ubiquitinbinding properties of the UBA domains of $c-C b l$ and $\mathrm{Cbl-b} .{ }^{61}$

Some mechanisms involved in the effects of $\mathrm{c}-\mathrm{Cbl}$ and Cbl-b in osteoclasts have been identified. ${ }^{71}$ The extinction of c-Cbl expression decreases osteoclast motility, adhesion and resorbing activity by modulating the degradation of Src kinase. ${ }^{62,67,72,73}$ In contrast, Cbl-b overexpression decreases osteoclast activity by regulating NF- $\kappa \mathrm{B}, \mathrm{ERK}$ and p38 signaling pathways. ${ }^{69}$ Also, c-Cbl promotes osteoclast survival by ubiquitylating Bim, a pro-apoptotic BH3-only $\mathrm{Bcl}-2$ family member. ${ }^{74}$ Osteoclast survival is also controlled by the interaction of $\mathrm{c}-\mathrm{Cbl}$ with $\mathrm{PI} 3 \mathrm{~K}$. A mutant form of $\mathrm{c}-\mathrm{Cbl}$ abrogating the interaction between $\mathrm{c}-\mathrm{Cbl}$ and $\mathrm{PI}$ K leads to decreased osteoclast activity and bone resorption, resulting in increased bone volume in mice. ${ }^{75}$ In addition to these functions, Cbl proteins modulate the assembly of signaling proteins downstream of the M-CSF receptor (c-Fms) and RANK that are required for osteoclastogenesis. ${ }^{70}$ Thus, both $\mathrm{c}-\mathrm{Cbl}$ and $\mathrm{Cbl}-\mathrm{b}$ control osteoclast activity through distinct ubiquitylation-dependent mechanisms, and some functions of one $\mathrm{Cbl}$ protein cannot be compensated by the other homolog. ${ }^{69}$ These studies underscore the multifunctional roles of $\mathrm{Cbl}$ proteins in the control of essential molecules regulating osteoclastogenesis and bone resorption.

\section{Role of Cbl E3 Ubiquitin Ligases in Bone-Forming Cells}

Recent studies have emphasized the role of $\mathrm{Cbl}$ proteins in osteoblastogenesis and bone formation. The analysis of c-Cbl $-/$ - and Cbl-b-/ - mice did not reveal detectable changes in bone formation, ${ }^{66}$ possibly because of redundancy of the two isoforms in osteoblast precursor cells and in mature osteoblasts. However, studies carried out in normal and pathological conditions revealed that $\mathrm{Cbl}$ proteins regulate the degradation of proteins that control osteoblasts (Figure 2b). After activation of receptor tyrosine kinases (RTKs), c-Cbl forms complexes with $\mathrm{PI} 3 \mathrm{~K}$ through interactions between $\mathrm{SH} 2$ and $\mathrm{SH} 3$ domains and the proline-rich region of c-Cbl. ${ }^{53}$ The first demonstration that $\mathrm{c}-\mathrm{Cb}$ controls osteoblastic cell
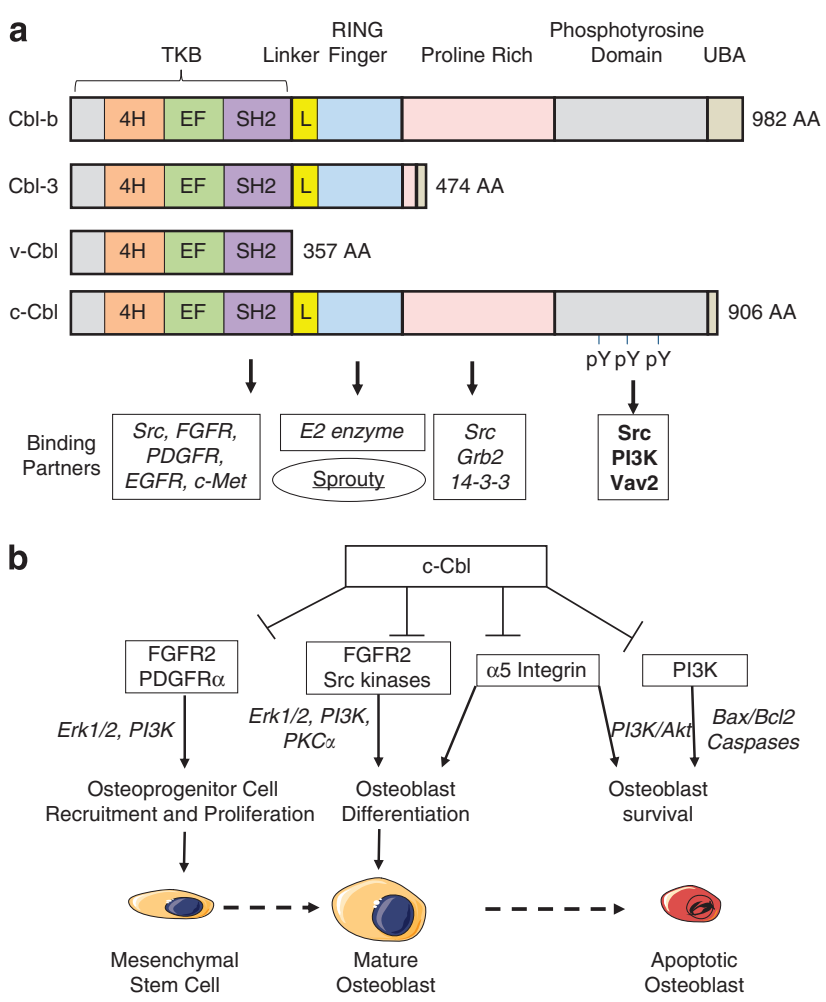

Figure 2 Role of $\mathrm{c}-\mathrm{Cbl}$ in the regulation of bone-forming cells. (a) The $\mathrm{Cbl}$ family is composed of three isoforms in mammalians (c-Cbl, Cbl-b and $\mathrm{Cbl}-3$ ) and one oncogenic form $(\mathrm{v}-\mathrm{Cbl})$. The multiadaptor protein $\mathrm{c}-\mathrm{Cbl}$ is composed of different domains that confer the specificity of interaction with target proteins. The tyrosine kinase binding domain (TKB) allows for the interaction with phosphorylated tyrosines and is composed of three interacting regions: a four helix bundle $(4 \mathrm{H})$, a $\mathrm{Ca} 2+$ binding EF hand (EF) and a variant Src homology 2 domain (SH2). The linker region (L) links the TKB and the RING domains, which allows for its interaction with E2 enzymes and sprouty2. The linker region and the RING domain are essential for the ubiquitin ligase activity of c-Cbl. The phosphotyrosine domain is phosphorylated by Src kinases. The proline-rich region allows for its interaction with SH3 domain-containing proteins, and the ubiquitin-associated domain (UBA) interacts with ubiquitin proteins. These domains interact with proteins that are targets of c-Cbl (italics), proteins that are able to phosphorylate c-Cbl (bold) and other proteins that can regulate $\mathrm{c}-\mathrm{Cbl}$ (underlined). (b) c-Cbl proteins control boneforming cells at different stages of differentiation. $\mathrm{c}-\mathrm{Cb}$ regulates cell growth and differentiation of osteoprogenitor cells, modulates osteogenic differentiation in more mature osteoblasts and controls cell death in differentiated osteoblasts. These effects are mediated by ubiquitination and degradation by the ubiquitin proteasome system (UPS) of the indicated RTKs and other molecules such as some integrins, resulting in the modulation of downstream signaling pathways controlling cell fate

proliferation came from our finding that the expression of a mutant G306ECbl that abrogates the interaction between $\mathrm{c}-\mathrm{Cbl}$ and RTKs increases human mesenchymal stromal cell (MSC) proliferation. ${ }^{76}$ In bone, PI3K controls osteoblasts by interacting with various molecules. ${ }^{77}$ Specific inhibition of the $\mathrm{PI} 3 \mathrm{~K} / \mathrm{c}-\mathrm{Cbl}$ interaction using a mutant Y737F c-Cbl increased osteoblastic cell proliferation, osteoblast number and bone volume in vivo, showing that abrogation of the c-Cbl-PI3K interaction leads to increased bone formation. ${ }^{78} \mathrm{~A}$ role for $\mathrm{c}-\mathrm{Cbl}$ in osteoblastic cell proliferation is also supported by our analysis of the Saethre-Chotzen syndrome, a human disease characterized by premature fusion of the cranial sutures induced by Twist 1 haploinsufficiency. ${ }^{79}$ In this disease, c-Cbl 
expression is decreased in osteoblasts, resulting in increased PI3K/Akt signaling and increased osteoblastic cell proliferation that contributes to the disease. ${ }^{80}$ These results indicate that $\mathrm{c}$-Cbl downregulates osteoblastic cell proliferation by interacting with targeted proteins such as PI3K (Figure $2 \mathrm{~b}$ ).

In addition to negatively regulating cell proliferation, $\mathrm{Cbl}$ proteins regulate osteoblast differentiation through ubiquitination and degradation of RTKs and other molecules. After binding of their ligands, RTKs are downregulated, resulting in their ubiquitination and degradation by the proteasome or lysosomes. ${ }^{64}$ This mechanism is an essential mechanism that negatively controls activated signaling pathways. ${ }^{81}$ The recruitment of $\mathrm{c}-\mathrm{Cbl}$ to $\mathrm{RTKs}$ allows polyubiquitination of several RTKs. ${ }^{82-86}$ This effect involves the phosphotyrosinebinding domain of $\mathrm{c}-\mathrm{Cbl}$ that binds to the activated receptor and the RING domain that is required for ubiquitination. ${ }^{52,59}$ In bone, RTKs such as insulin-like growth factor receptor (IGFR), ${ }^{87,88}$ fibroblast growth factor receptor (FGFR), ${ }^{89,90}$ epidermal growth factor receptor (EGFR) and platelet growth factor receptor (PDGFR), ${ }^{91,92}$ play major roles in the control of osteoblastogenesis and bone formation. Therefore, c-Cblmediated degradation of these RTKs may be a regulatory mechanism controlling osteoblast function. This hypothesis is supported by our finding that a mutant G306ECbl that abrogates c-Cbl-RTK interaction in human MSCs decreased FGFR2 and PDGFR- $\alpha$ receptor ubiquitination and degradation, resulting in increased expression of these receptors and activation of downstream ERK1/2 and PI3K signaling pathways that in turn promoted osteoblast differentiation and in vitro osteogenesis ${ }^{76}$ (Figure 3 ).

The interaction of $\mathrm{c}$-Cbl with RTKs may also play an important role in the control of osteogenesis in pathological

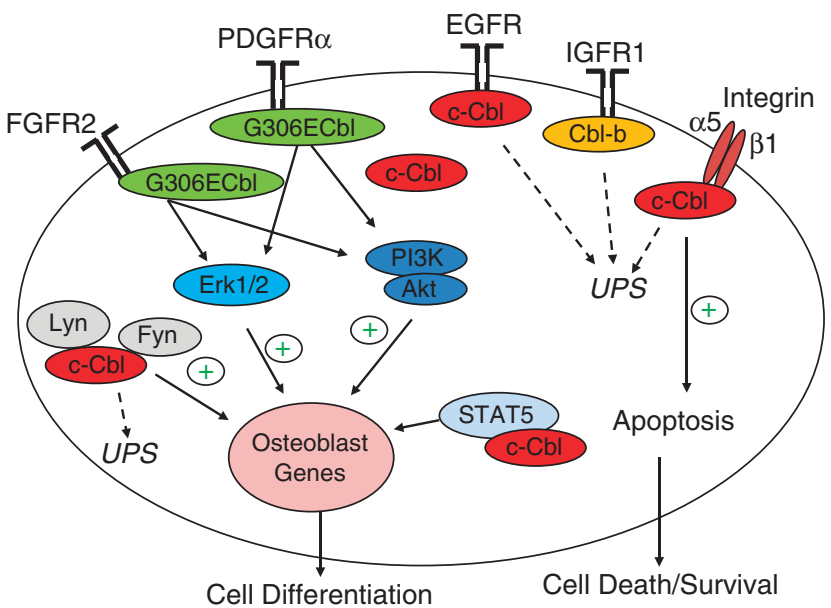

Figure 3 Signaling pathways and mechanisms involved in c-Cbl-mediated control of bone forming cells. The E3 ubiquitin ligase c-Cbl mediates Lyn and Fyn ubiquitination and degradation by the proteasome ubiquitin system (UPS), resulting in increased osteoblast differentiation. c-Cbl induces ubiquitination and degradation of $\mathrm{PI} 3 \mathrm{~K}$ and $\alpha 5$ integrin, resulting in cell apoptosis. Abrogating the interaction between c-Cbl and FGFR2 and PDGFR- $\alpha$ by a c-Cbl mutant (G306E) promotes mesenchymal cell proliferation and osteoblast differentiation mediated by increased ERK1/2 and PI3K signaling. C-Cbl regulates the ubiquitination and degradation of the transcription factor STAT5 in mesenchymal osteoprogenitor cells and thereby promotes bone-forming cell differentiation. The isoform $\mathrm{Cbl}-\mathrm{b}$ mediates ubiquitination and degradation of IGFR1 receptors and downregulates osteoblastogenesis (see the text for details) conditions. Apert syndrome is a human disease characterized by premature fusion of cranial sutures (craniostenosis) induced by constitutive activation of FGFR2. ${ }^{93}$ This effect results in increased osteoblast differentiation and cranial osteogenesis. $^{94}$ Among the mechanisms involved in this effect, we found that activated FGFR2 enhances EGFR and PDGFR- $\alpha$ mRNA expression via activation of PKC- $\alpha$-dependent AP-1 transcriptional activity. ${ }^{95-97}$ The increased EGFR protein expression in mutant osteoblasts also results from a posttranscriptional mechanism involving increased Sprouty2c-Cbl interaction due to FGFR2 constitutive activation, which leads to $\mathrm{c}-\mathrm{Cbl}$ sequestration and reduced EGFR ubiquitination. ${ }^{98}$ These studies identified molecular crosstalks between c-Cbl, activated FGFR2 and EGFR and PDGFR- $\alpha$ expression that functionally contribute to the regulation of osteoblast functions ${ }^{99}$ (Figure 3).

In addition to controlling RTK degradation, c-Cbl regulates the ubiquitination and degradation of proteins acting downstream of RTK signaling such as Src nonreceptor tyrosine kinases. Src may act as an adapter protein that links other signaling proteins within complexes, or as a tyrosine kinase that phosphorylates some components of these complexes. ${ }^{70}$ These activities are mediated by the $\mathrm{SH} 2$ domain that binds specific proline-containing motifs, the $\mathrm{SH} 2$ domain that binds phosphotyrosine, and the kinase domain. ${ }^{73}$ The binding of proteins to $\mathrm{SH} 2$ and $\mathrm{SH} 3$ can allow a switch from an inactive to an active state, leading to Src auto-phosphorylation and activation. The binding of $\mathrm{c}-\mathrm{Cb}$ to Src leads to Src inactivation via its ubiquitination and degradation. ${ }^{62,100}$ Src-like kinases are substrates of activated $\mathrm{Cbl}$ in response to RTK activation, leading to the phosphorylation of a tyrosine residue in $\mathrm{Cbl}$ that may regulate activation of $\mathrm{PI} 3 \mathrm{~K}^{60}$ In osteoblasts, the interaction of Src and $\mathrm{c}-\mathrm{Cbl}$ is functional as we found that constitutive activation of FGFR2 leads to c-Cbl-dependent ubiquitination and degradation of the Src proteins Lyn and Fyn, resulting in abnormally increased osteoblast function and osteogenesis. ${ }^{101}$ Disruption of the c-CbI RING domain or TKB domain can restore Src kinase activity, resulting in decreased osteoblastic function. Thus, c-Cbl-mediated Src protein degradation plays a role in the excessive bone formation induced by overactive FGFR2. ${ }^{101}$

Another mechanism by which c-Cbl may control osteoblastogenesis is through the activation of transcription factors directing osteogenesis. Notably, we recently showed that silencing $\mathrm{c}-\mathrm{Cbl}$ expression in human MSCs promoted osteoblast differentiation and in vitro osteogenesis. This effect resulted in part from decreased c-Cbl-mediated ubiquitination and degradation of the transcription factor STAT5 that positively interacts with Runx2 and thereby enhances osteoblast differentiation (F-X Dieudonné et al., submitted). Overall, these results underscore the regulatory role of $c-C b l$ in osteoblastogenesis and bone formation through various c-Cbl-mediated mechanisms (Figure 3).

Given that the ubiquitin proteasome system is involved in the control of apoptosis, ${ }^{102,103}$ it is not surprising that $\mathrm{c}-\mathrm{Cbl}$ may control osteoblast survival in addition to its role in regulating cell proliferation and differentiation. Two mechanisms have been identified to date involving $\mathrm{c}-\mathrm{Cbl}$-mediated regulation of proteins controlling bone-forming cell apoptosis. We showed that the $\mathrm{c}-\mathrm{Cbl}$ recruitment induced by FGFR2 
activation triggers proteasome degradation of the $\alpha 5$ integrin subunit, resulting in decreased integrin expression, reduced osteoblast attachment and increased apoptosis. ${ }^{104} \mathrm{PI}$ K and c-Cbl are known to interact with growth factors in the cell membrane microdomains called lipid rafts that serve as platforms where signaling molecules are recruited to membrane-associated kinases, allowing functional interactions. ${ }^{105,106}$ We showed that FGFR2 activation in osteoblasts leads to $\mathrm{c}-\mathrm{Cbl}$ recruitment associated with PI3K/Akt in lipid rafts. This effect results in PI3K ubiquitination and degradation, attenuation of PI3K/Akt signaling and increased osteoblast apoptosis in vitro and in vivo. ${ }^{107,108}$ Conversely, a mutant G306ECbl that abrogates c-Cbl-RTK interaction was shown to protect human MSCs from apoptosis. ${ }^{76}$ Overall, these findings support a role of $\mathrm{c}-\mathrm{Cbl}$ in the control of osteoblast survival through modulation of PI3K/Akt and integrin degradation (Figure 3).

Besides $c-C b l$, there is also evidence that $\mathrm{Cbl}-\mathrm{b}$ is involved in the control of osteoblast function. In vitro, Cbl-b was shown to enhance Runx2 protein stability and osteoblast-related genes, indicating that Cbl-b may control osteoblast differentiation at the posttranscriptional level. ${ }^{109}$ In vivo, bone loss induced by denervation in mice is associated with increased Cbl-b expression and decreased insulin receptor substrate-1 (IRS-1), PI3K and Akt levels in osteoblastic cells, a phenotype that is prevented in Cbl-b-deficient mice. One mechanism by which Cbl-b may downregulate bone formation is through modulation of IGF signaling because Cbl-b overexpression induces IRS-1 ubiquitination and degradation, resulting in impaired mitogenic response to IGF1. ${ }^{110}$ Overall, these studies indicate that $\mathrm{Cbl}$ proteins control osteoblast proliferation, differentiation and survival through the ubiquitination and degradation of RTKs and other c-Cbl-targeted proteins (Figure 3).

\section{Cbl-Mediated Ubiquitination: A Potential Target for Therapeutic Intervention}

Because the ubiquitination/degradation system controls many cellular processes, targeting proteins involved in this mechanism may provide therapeutic clues in pathological conditions. As discussed above, proteasome inhibitors were shown to increase bone formation while reducing bone resorption. ${ }^{18,19,22}$ A more specific approach for promoting bone formation may be to directly target E3 ubiquitin ligases that control osteoblastogenesis. In support of this concept, we recently showed that inhibition of $c-C b l$ activity using shRNA in murine and human MSCs promoted osteoblast differentiation and survival through activation of RTK signaling ${ }^{76}$ and STAT5-Runx2 transcriptional activity (F-X Dieudonné et al., submitted) (Figure 4). This finding may have functional implications as specific inhibitors of the interactions between c-Cbl and RTK have been recently identified. Notably, a pentapeptide was found to bind the $\mathrm{c}-\mathrm{CbI}$ TKB domain with high affinity. ${ }^{111}$ Targeting the interaction between $\mathrm{Cbl}$ and target proteins using this or other molecules may be an attractive strategy to activate osteoblastogenesis.

Several dysfunctions of the UPS lead to a large number of pathologies such as cancer. This may be because of an increased ubiquitination and degradation of tumor-suppressor

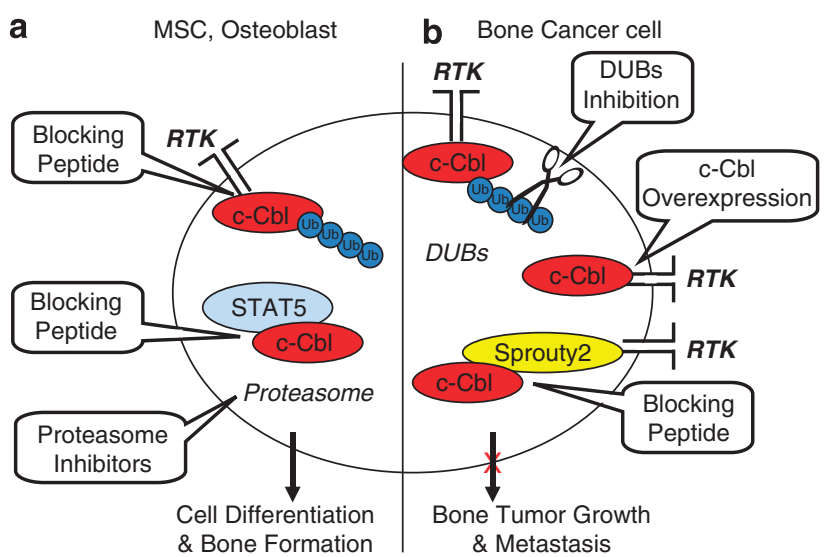

Figure 4 Proposed strategies targeting c-Cbl ubiquitin ligase activity to promote bone-forming cell differentiation and to decrease bone tumorigenesis. (a) Inhibition of the proteasome by inhibitors (i.e., Bortezomib) results in increased bone-forming cell differentiation and bone formation. A more specific strategy to reduce ubiquitination is to abrogate the interaction between $\mathrm{c}-\mathrm{Cb}$ and RTKs or specific transcription factors, such as STAT5, by using blocking peptides. (b) In primary bone cancer, increasing ubiquitination and degradation of RTKs by ectopic $c-C b l$ expression reduces tumorigenesis. Increasing Cbl activity could also be achieved by blocking the interaction between $\mathrm{c}-\mathrm{Cbl}$ and Sprouty2 that sequesters $\mathrm{c}-\mathrm{Cbl}$ away from activated RTKs. An alternative strategy for increasing c-Cbl-mediated ubiquitination of oncogenic proteins is to inhibit deubiquitinases (DUBs) that remove ubiquitin chains linked to target proteins

proteins or a decrease in ubiquitination of oncogenic proteins. ${ }^{112}$ Therefore, targeting the ubiquitin-proteasome system may represent a valid therapeutic strategy in cancers. ${ }^{113-115}$ In support of this concept, proteasome inhibitors were efficient at reducing tumorigenesis, ${ }^{114,116}$ specifically in myeloid disorders. ${ }^{17,32}$ Proteasome inhibition was also shown to reduce breast cancer tumor growth. ${ }^{117}$ However, some cancers are resistant to proteasome inhibitors and more selective strategies are needed to circumvent this limitation. ${ }^{118}$ One emerging aspect in tumorigenesis is the implication of E3 ubiquitin ligases ${ }^{119,120}$ that control cancer cell adhesion, migration and metastasis. ${ }^{121} \mathrm{~A}$ potential target is $\mathrm{c}-\mathrm{Cbl}$ that is implicated in different cancers. Genetic mutations localized in the RING or the linker domain of $\mathrm{c}-\mathrm{Cbl}$ are known to cause myelodysplasia and acute myeloid leukemia in children. ${ }^{122}$ Additionally, several oncogenic RTKs have lost their Cbl-binding sites and thereby escape downregulation following ligand stimulation, leading to human tumors. ${ }^{123}$ Although $\mathrm{Cbl}$ activity is inhibited in lung cancer, ${ }^{124}$ it is increased in breast cancer, ${ }^{125}$ indicating that Cbl can act as an oncogene or a tumor-suppressor protein depending on its interaction with target proteins. In lung cancer, c-Cbl overexpression inhibits tumor metastasis and tumor growth in vivo, indicating that $\mathrm{c}-\mathrm{Cbl}$ can be targeted to reduce tumorigenesis. ${ }^{126}$

Recent data indicate that $\mathrm{c}-\mathrm{Cbl}$ may play a role is osteosarcoma, a primary bone tumor occuring in children and young adults. Various loss-of-function mutations in p53 and/or pRB tumor-suppressor genes have been found in osteosarcoma ${ }^{127}$ and both tumor suppressors have been linked to the expression and/or activity of Runx2. ${ }^{128}$ Dysregulations of Runx2 cause abnormal cell growth and differentiation. ${ }^{129-132}$ Therefore, targeting Runx2 may lead to 
inhibition of tumor propagation. ${ }^{133}$ Indeed, the inhibition of the proteasome in osteosarcoma cells can increase Runx2, reduce cell growth and increase cell apoptosis, resulting in bone tumor regression in vivo. ${ }^{134}$ On the other hand, RTK expression was found to be increased in some osteosarcoma, and pharmacological inhibitors or specific RTK blocking antibodies in combination with chemotherapy could reduce bone tumor formation and metastasis. ${ }^{135}$ Consistently, we recently showed that $\mathrm{c}-\mathrm{Cb}$ protein expression is decreased in face of increased EGFR and PDGFR- $\alpha$ expression in human osteosarcoma tumors compared with normal bone. ${ }^{136}$ This finding has therapeutic implications as ectopic c-Cbl expression in osteosarcoma cells could reduce the expression of EGFR and PDGFR- $\alpha$, resulting in decreased cell proliferation and survival, and reduced incidence of lung metastasis in mice. ${ }^{136}$ Thus, promoting RTK ubiquitination and degradation by targeting $\mathrm{c}-\mathrm{Cbl}$ may prove to be efficient at reducing tumor growth and metastasis in cancers in which RTK expression is excessive (Figure 4). This strategy may also be applied to Ewing sarcoma that is associated with increased IGF receptor activity. ${ }^{137}$

Another potential strategy to increase RTK degradation in cancers is to inhibit the interaction between $\mathrm{c}-\mathrm{Cbl}$ and its negative regulators. ${ }^{55}$ For example, inhibiting the interaction between c-Cbl and Sprouty 2, which sequesters c-Cbl away from activated RTKs, may lead to increase c-Cbl available for interacting with RTKs (Figure 4). An alternative indirect strategy to downregulate the aberrant signaling in cancers would be to target deubiquitinases that are negative regulators of the ubiquitin cascade. ${ }^{138}$ These enzymes break ubiquitin chains that are linked to the targeted proteins, thereby avoiding the degradation of the targeted proteins. ${ }^{4}$ DUB dysregulations have been associated with human cancers, where they may act as oncogenes or tumor suppressors depending on the substrate, suggesting that DUBs may be targeted in cancer therapeutics. ${ }^{120,138}$ This proposal is supported by the finding that downregulation of the deubiquitinating enzyme USP9X, which interacts with $\mathrm{c}-\mathrm{Cbl}$ and the cancer-related ErbB2/HER2 receptor, results in increased ErbB2 degradation in cancer cells. ${ }^{139} \mathrm{~A}$ recent study showed that the deubiquitinase USP1, which acts by maintaining MSCs in a proliferative stage and inhibiting their osteogenic differentiation, is overexpressed and promotes the stability of the oncogenic protein ID2 in osteosarcoma cells. Interestingly, USP1 knockdown causes osteoblast differentiation in these cells. ${ }^{140}$ It is thus possible that inhibitors of the activity of specific DUBs may enhance the degradation of specific substrates such as RTKs and thereby reduce cell tumorigenicity and bone tumor development (Figure 4).

\section{Conclusion}

The ubiquitination system is an important mechanism regulating protein degradation. This system is highly involved in the regulation of cell proliferation, differentiation and survival, and dysregulations in this system often lead to pathologies such as cancers. Recent studies have underscored the role of E3 ubiquitin ligases in the control of bone cell functions and tumorigenesis. Some advances have been made in the understanding of the role of these ligases in the regulation of signaling pathways and transcription factors that control osteoblast differentiation and survival. Key proteins that interact with the E3 ubiquitin ligase $\mathrm{c}-\mathrm{Cbl}$ and are regulated by $\mathrm{c}-\mathrm{Cbl}$-mediated degradation have been identified. Targeting the interactions between the identified proteins and $\mathrm{c}-\mathrm{Cbl}$ proved to be efficient in modulating $\mathrm{c}-\mathrm{Cbl}$ functions with subsequent changes in cell proliferation, differentiation and survival in normal osteoprogenitor cells and in bone tumor cells. This knowledge may pave the way for developing therapeutic strategies targeting c-Cbl interaction with specific substrates with the goal of promoting osteoblast function in diseases characterized by defective bone formation, or for correcting the abnormal osteoblast differentiation and reducing tumorigenesis in bone cancers.

\section{Conflict of Interest}

The authors declare no conflict of interest.

Acknowledgements. This work was supported in part by Inserm, the Ministère de la Recherche and the Agence Nationale de la Recherche (ANR-09BLAN-0402CSD8 Promotos) (Paris, France). We thank Dr. Zuzana Saidak for language correction of the manuscript.

1. Ciechanover A. Intracellular protein degradation: from a vague idea, through the lysosome and the ubiquitin-proteasome system, and onto human diseases and drug targeting. Cell Death Differ 2005; 12: 1178-1190.

2. Komander D. The emerging complexity of protein ubiquitination. Biochem Soc Trans 2009; 37(Pt 5): 937-953.

3. Dikic I, Wakatsuki S, Walters KJ. Ubiquitin-binding domains - from structures to functions. Nat Rev Mol Cell Biol 2009; 10: 659-671.

4. Komander D, Clague MJ, Urbe S. Breaking the chains: structure and function of the deubiquitinases. Nat Rev Mol Cell Biol 2009; 10: 550-563.

5. Ciechanover A. The ubiquitin proteolytic system: from an idea to the patient bed. Proc Am Thorac Soc 2006; 3: 21-31

6. Dikic I, Robertson M. Ubiquitin ligases and beyond. BMC Biol 2012; 10: 22.

7. Husnjak K, Dikic I. Ubiquitin-binding proteins: decoders of ubiquitin-mediated cellular functions. Annu Rev Biochem 2012; 81: 291-322.

8. de Bie P, Ciechanover A. Ubiquitination of E3 ligases: self-regulation of the ubiquitin system via proteolytic and non-proteolytic mechanisms. Cell Death Differ 2011; 18: 1393-1402.

9. Edwards JR, Mundy GR. Advances in osteoclast biology: old findings and new insights from mouse models. Nat Rev Rheumatol 2011; 7: 235-243.

10. Harada S, Rodan GA. Control of osteoblast function and regulation of bone mass. Nature 2003; 423: 349-355.

11. Lian JB, Stein GS, Stein JL, van Wijnen AJ. Transcriptional control of osteoblast differentiation. Biochem Soc Trans 1998; 26: 14-21.

12. Marie PJ. Transcription factors controlling osteoblastogenesis. Arch Biochem Biophys 2008; 473: 98-105.

13. Manolagas SC. Birth and death of bone cells: basic regulatory mechanisms and implications for the pathogenesis and treatment of osteoporosis. Endocr Rev 2000; 21: $115-137$.

14. Lian JB, Stein GS. Runx2/Cbfa1: a multifunctional regulator of bone formation. Curr Pharm Des 2003; 9: 2677-2685.

15. Teti A. Bone development: overview of bone cells and signaling. Curr Osteoporos Rep 2011; 9: 264-273.

16. Wu S, De Luca F. Inhibition of the proteasomal function in chondrocytes down-regulates growth plate chondrogenesis and longitudinal bone growth. Endocrinology 2006; 147: 3761-3768

17. Yaccoby S. Osteoblastogenesis and tumor growth in myeloma. Leuk Lymphoma 2010; 51: 213-220.

18. Mukherjee S, Raje N, Schoonmaker JA, Liu JC, Hideshima T, Wein MN et al. Pharmacologic targeting of a stem/progenitor population in vivo is associated with enhanced bone regeneration in mice. J Clin Invest 2008; 118: 491-504.

19. Giuliani N, Morandi F, Tagliaferri S, Lazzaretti M, Bonomini S, Crugnola M et al. The proteasome inhibitor bortezomib affects osteoblast differentiation in vitro and in vivo in multiple myeloma patients. Blood 2007; 110: 334-338.

20. Oyajobi BO, Garrett IR, Gupta A, Flores A, Esparza J, Munoz S et al. Stimulation of new bone formation by the proteasome inhibitor, bortezomib: implications for myeloma bone disease. Br J Haematol 2007; 139: 434-438. 
21. Uy GL, Trivedi R, Peles S, Fisher NM, Zhang QJ, Tomasson MH et al. Bortezomib inhibits osteoclast activity in patients with multiple myeloma. Clin Lymphoma Myeloma 2007; 7 : 587-589.

22. Terpos E, Sezer O, Croucher P, Dimopoulos MA. Myeloma bone disease and proteasome inhibition therapies. Blood 2007; 110: 1098-1104.

23. Goldring MB, Tsuchimochi K, ljiri K. The control of chondrogenesis. J Cell Biochem 2006; 97: 33-44

24. Krishnan V, Bryant HU, Macdougald OA. Regulation of bone mass by Wnt signaling. $J$ Clin Invest 2006; 116: 1202-1209.

25. Nusse R. Wnt signaling in disease and in development. Cell Res 2005; 15: 28-32.

26. Zaman F, Menendez-Benito V, Eriksson E, Chagin AS, Takigawa M, Fadeel B et al. Proteasome inhibition up-regulates p53 and apoptosis-inducing factor in chondrocytes causing severe growth retardation in mice. Cancer Res 2007; 67: 10078-10086.

27. Qiang YW, Hu B, Chen Y, Zhong Y, Shi B, Barlogie B et al. Bortezomib induces osteoblast differentiation via Wnt-independent activation of beta-catenin/TCF signaling. Blood 2009; 113: 4319-4330.

28. Garrett IR, Chen D, Gutierrez G, Zhao M, Escobedo A, Rossini G et al. Selective inhibitors of the osteoblast proteasome stimulate bone formation in vivo and in vitro. J Clin Invest 2003; 111: 1771-1782.

29. Zhao M, Qiao M, Harris SE, Chen D, Oyajobi BO, Mundy GR. The zinc finger transcription factor Gli2 mediates bone morphogenetic protein 2 expression in osteoblasts in response to hedgehog signaling. Mol Cell Biol 2006; 26: 6197-6208.

30. von Metzler I, Krebbel H, Hecht M, Manz RA, Fleissner C, Mieth M et al. Bortezomib inhibits human osteoclastogenesis. Leukemia 2007; 21: 2025-2034.

31. Ang E, Pavlos NJ, Rea SL, Qi M, Chai T, Walsh JP et al. Proteasome inhibitors impair RANKL-induced NF-kappaB activity in osteoclast-like cells via disruption of p62, TRAF6, CYLD, and IkappaBalpha signaling cascades. J Cell Physiol 2009; 220: 450-459.

32. Pennisi A, Li X, Ling W, Khan S, Zangari M, Yaccoby S. The proteasome inhibitor, bortezomib suppresses primary myeloma and stimulates bone formation in myelomatous and nonmyelomatous bones in vivo. Am J Hematol 2009; 84: 6-14.

33. Zhao M, Qiao M, Oyajobi BO, Mundy GR, Chen D. E3 ubiquitin ligase Smurf1 mediates core-binding factor alpha1/Runx2 degradation and plays a specific role in osteoblast differentiation. J Biol Chem 2003; 278: 27939-27944.

34. Zhao M, Qiao M, Harris SE, Oyajobi BO, Mundy GR, Chen D. Smurf1 inhibits osteoblast differentiation and bone formation in vitro and in vivo. J Biol Chem 2004; 279 : 12854-12859.

35. Zhao L, Huang J, Guo R, Wang Y, Chen D, Xing L. Smurf1 inhibits mesenchymal stem cell proliferation and differentiation into osteoblasts through JunB degradation. $J$ Bone Miner Res 2010; 25: 1246-1256.

36. Kaneki H, Guo R, Chen D, Yao Z, Schwarz EM, Zhang YE et al. Tumor necrosis factor promotes Runx2 degradation through up-regulation of Smurf1 and Smurf2 in osteoblasts. J Biol Chem 2006; 281: 4326-4333.

37. Guo R, Yamashita M, Zhang Q, Zhou Q, Chen D, Reynolds DG et al. Ubiquitin ligase Smurf1 mediates tumor necrosis factor-induced systemic bone loss by promoting proteasomal degradation of bone morphogenetic signaling proteins. J Biol Chem 2008; 283: 23084-23092.

38. Glimcher LH, Jones DC, Wein MN. Control of postnatal bone mass by the zinc finger adapter protein Schnurri-3. Ann N Y Acad Sci 2007; 1116: 174-181.

39. Jeon EJ, Lee KY, Choi NS, Lee MH, Kim HN, Jin YH et al. Bone morphogenetic protein-2 stimulates Runx2 acetylation. J Biol Chem 2006; 281: 16502-16511.

40. Zhu H, Kavsak P, Abdollah S, Wrana JL, Thomsen GH. A SMAD ubiquitin ligase targets the BMP pathway and affects embryonic pattern formation. Nature 1999; 400: 687-693.

41. Zhang G, Guo B, Wu $H$, Tang $T$, Zhang BT, Zheng $L$ et al. A delivery system targeting bone formation surfaces to facilitate RNAi-based anabolic therapy. Nat Med 2012; 18 307-314.

42. Bellido T, Ali AA, Plotkin LI, Fu Q, Gubrij I, Roberson PK et al. Proteasomal degradation of Runx2 shortens parathyroid hormone-induced anti-apoptotic signaling in osteoblasts. A putative explanation for why intermittent administration is needed for bone anabolism. J Biol Chem 2003; 278: 50259-50272.

43. Yamashita M, Ying SX, Zhang GM, Li C, Cheng SY, Deng CX et al. Ubiquitin ligase Smurf1 controls osteoblast activity and bone homeostasis by targeting MEKK2 for degradation. Cell 2005; 121: 101-113.

44. Li X, Huang M, Zheng $\mathrm{H}$, Wang $\mathrm{Y}$, Ren $\mathrm{F}$, Shang $\mathrm{Y}$ et al. CHIP promotes Runx2 degradation and negatively regulates osteoblast differentiation. J Cell Biol 2008; 181 : 959-972.

45. Jones DC, Wein MN, Oukka M, Hofstaetter JG, Glimcher MJ, Glimcher LH. Regulation of adult bone mass by the zinc finger adapter protein Schnurri-3. Science 2006; 312 : 1223-1227.

46. Zhao L, Huang J, Zhang $\mathrm{H}$, Wang $\mathrm{Y}$, Matesic LE, Takahata $\mathrm{M}$ et al. Tumor necrosis factor inhibits mesenchymal stem cell differentiation into osteoblasts via the ubiquitin E3 ligase Wwp1. Stem Cells 2011; 29: 1601-1610.

47. Yang X, Karsenty G. ATF4, the osteoblast accumulation of which is determined post-translationally, can induce osteoblast-specific gene expression in non-osteoblastic cells. J Biol Chem 2004; 279: 47109-47114.

48. Kim M, Nakamoto T, Nishimori S, Tanaka K, Chiba T. A new ubiquitin ligase involved in p57KIP2 proteolysis regulates osteoblast cell differentiation. EMBO Rep 2008; 9 : 878-884.
49. Dikic I, Szymkiewicz I, Soubeyran P. Cbl signaling networks in the regulation of cell function. Cell Mol Life Sci 2003; 60: 1805-1827.

50. Swaminathan G, Tsygankov AY. The Cbl family proteins: ring leaders in regulation of cell signaling. J Cell Physiol 2006; 209: 21-43.

51. Mohapatra B, Ahmad G, Nadeau S, Zutshi N, An W, Scheffe S et al. Protein tyrosine kinase regulation by ubiquitination: Critical roles of $\mathrm{Cbl}$-family ubiquitin ligases. Biochim Biophys Acta 2013; 1833: 122-139.

52. Thien CB, Langdon WY. Cbl: many adaptations to regulate protein tyrosine kinases. Nat Rev Mol Cell Biol 2001; 2: 294-307.

53. Tsygankov AY, Teckchandani AM, Feshchenko EA, Swaminathan G. Beyond the RING: CBL proteins as multivalent adapters. Oncogene 2001; 20: 6382-6402.

54. Schmidt MH, Dikic I. The Cbl interactome and its functions. Nat Rev Mol Cell Biol 2005; 6 : 907-919.

55. Haglund K, Schmidt MH, Wong ES, Guy GR, Dikic I. Sprouty2 acts at the Cbl/CIN85 interface to inhibit epidermal growth factor receptor downregulation. EMBO Rep 2005; 6 : 635-641.

56. Kassenbrock CK, Anderson SM. Regulation of ubiquitin protein ligase activity in c-Cbl by phosphorylation-induced conformational change and constitutive activation by tyrosine to glutamate point mutations. J Biol Chem 2004; 279: 28017-28027.

57. Dou H, Buetow L, Hock A, Sibbet GJ, Vousden KH, Huang DT. Structural basis for autoinhibition and phosphorylation-dependent activation of c-Cbl. Nat Struct Mol Biol 2012; 19: 184-192.

58. Kales SC, Ryan PE, Lipkowitz S. Cbl exposes its RING finger. Nat Struct Mol Biol 2012; 19: 131-133.

59. Thien CB, Langdon WY. Negative regulation of PTK signalling by Cbl proteins. Growth Factors 2005; 23: 161-167.

60. Hunter S, Burton EA, Wu SC, Anderson SM. Fyn associates with Cbl and phosphorylates tyrosine 731 in Cbl, a binding site for phosphatidylinositol 3-kinase. J Biol Chem 1999; 274: 2097-2106.

61. Davies GC, Ettenberg SA, Coats AO, Mussante M, Ravichandran S, Collins J et al. Cbl-b interacts with ubiquitinated proteins; differential functions of the UBA domains of $\mathrm{c}-\mathrm{Cb}$ and Cbl-b. Oncogene 2004; 23: 7104-7115.

62. Sanjay A, Houghton A, Neff L, DiDomenico E, Bardelay C, Antoine E et al. Cbl associates with Pyk2 and Src to regulate Src kinase activity, alpha(v)beta(3) integrin-mediated signaling, cell adhesion, and osteoclast motility. J Cell Biol 2001; 152: 181-195.

63. Dikic I, Giordano S. Negative receptor signalling. Curr Opin Cell Biol 2003; 15: 128-135.

64. Rubin C, Gur G, Yarden Y. Negative regulation of receptor tyrosine kinases: unexpected links to $\mathrm{c}-\mathrm{Cbl}$ and receptor ubiquitylation. Cell Res 2005; 15: 66-71.

65. Naramura M, Jang IK, Kole H, Huang F, Haines D, Gu H. c-Cbl and Cbl-b regulate T cell responsiveness by promoting ligand-induced TCR down-modulation. Nat Immunol 2002 3: $1192-1199$

66. Chiusaroli R, Sanjay A, Henriksen K, Engsig MT, Horne WC, Gu H et al. Deletion of the gene encoding $\mathrm{c}-\mathrm{Cbl}$ alters the ability of osteoclasts to migrate, delaying resorption and ossification of cartilage during the development of long bones. Dev Biol 2003; 261: 537-547.

67. Bruzzaniti A, Neff L, Sanjay A, Horne WC, De Camilli P, Baron R. Dynamin forms a Src kinase-sensitive complex with $\mathrm{Cbl}$ and regulates podosomes and osteoclast activity. Mol Biol Cell 2005; 16: 3301-3313.

68. Meng $\mathrm{F}$, Lowell $\mathrm{CA}$. A beta 1 integrin signaling pathway involving Src-family kinases, $\mathrm{Cbl}$ and $\mathrm{PI}-3$ kinase is required for macrophage spreading and migration. EMBO J 1998; 17 4391-4403.

69. Nakajima A, Sanjay A, Chiusaroli R, Adapala NS, Neff L, Itzsteink C et al. Loss of Cbl-b increases osteoclast bone-resorbing activity and induces osteopenia. J Bone Miner Res 2009; 24: 1162-1172.

70. Horne WC, Sanjay A, Bruzzaniti A, Baron R. The role(s) of Src kinase and Cbl proteins in the regulation of osteoclast differentiation and function. Immunol Rev 2005; 208: $106-125$.

71. Purev E, Neff L, Horne WC, Baron R. c-Cbl and Cbl-b act redundantly to protect osteoclasts from apoptosis and to displace HDAC6 from beta-tubulin, stabilizing microtubules and podosomes. Mol Biol Cell 2009; 20: 4021-4030.

72. Tanaka S, Amling M, Neff L, Peyman A, Uhlmann E, Levy JB et al. $\mathrm{C}-\mathrm{Cb}$ is downstream of c-Src in a signalling pathway necessary for bone resorption. Nature 1996; 383: 528-531.

73. Yokouchi M, Kondo T, Sanjay A, Houghton A, Yoshimura A, Komiya S et al. Src-catalyzed phosphorylation of $\mathrm{c}-\mathrm{Cbl}$ leads to the interdependent ubiquitination of both proteins. $J \mathrm{BiO}$ Chem 2001; 276: 35185-35193.

74. Akiyama T, Bouillet $\mathrm{P}$, Miyazaki T, Kadono Y, Chikuda H, Chung UI et al. Regulation of osteoclast apoptosis by ubiquitylation of proapoptotic $\mathrm{BH}$-only $\mathrm{Bcl}-2$ family member Bim. EMBO J 2003; 22: 6653-6664

75. Adapala NS, Barbe MF, Langdon WY, Nakamura MC, Tsygankov AY, Sanjay A. The loss of Cbl-phosphatidylinositol 3-kinase interaction perturbs RANKL-mediated signaling inhibiting bone resorption and promoting osteoclast survival. J Biol Chem 2010; 285 36745-36758.

76. Sévère N, Miraoui H, Marie PJ. The Casitas B lineage lymphoma (Cbl) mutant G306E enhances osteogenic differentiation in human mesenchymal stromal cells in part by decreased $\mathrm{Cbl}$-mediated platelet-derived growth factor receptor alpha and fibroblast growth factor receptor 2 ubiquitination. J Biol Chem 2011; 286: 24443-24450.

77. Golden LH, Insogna KL. The expanding role of PI3-kinase in bone. Bone 2004; 34: 3-12. 
78. Brennan T, Adapala NS, Barbe MF, Yingling V, Sanjay A. Abrogation of Cbl-PI3K interaction increases bone formation and osteoblast proliferation. Calcif Tissue Int 2011 89: 396-410.

79. Yousfi M, Lasmoles F, Lomri A, Delannoy P, Marie PJ. Increased bone formation and decreased osteocalcin expression induced by reduced Twist dosage in Saethre-Chotzen syndrome. J Clin Invest 2001; 107: 1153-1161.

80. Guénou H, Kaabeche K, Dufour C, Miraoui H, Marie PJ. Down-regulation of ubiquitin ligase $\mathrm{Cbl}$ induced by twist haploinsufficiency in Saethre-Chotzen syndrome results in increased PI3K/Akt signaling and osteoblast proliferation. Am J Pathol 2006; 169 1303-1311.

81. Lemmon MA, Schlessinger J. Cell signaling by receptor tyrosine kinases. Cell 2010; 141 : 1117-1134.

82. Joazeiro CA, Wing SS, Huang H, Leverson JD, Hunter T, Liu YC. The tyrosine kinase negative regulator $\mathrm{c}-\mathrm{Cbl}$ as a RING-type, E2-dependent ubiquitin-protein ligase. Science 1999; 286: 309-312

83. Levkowitz G, Waterman H, Zamir E, Kam Z, Oved S, Langdon WY et al. c-Cbl/Sli-1 regulates endocytic sorting and ubiquitination of the epidermal growth factor receptor Genes Dev 1998; 12: 3663-3674.

84. Miyake S, Mullane-Robinson KP, Lill NL, Douillard P, Band H. Cbl-mediated negative regulation of platelet-derived growth factor receptor-dependent cell proliferation. A critical role for Cbl tyrosine kinase-binding domain. J Biol Chem 1999; 274: 16619-16628.

85. Yokouchi M, Kondo T, Houghton A, Bartkiewicz M, Horne WC, Zhang $\mathrm{H}$ et al. Ligand-induced ubiquitination of the epidermal growth factor receptor involves the interaction of the c-Cbl RING finger and UbcH7. J Biol Chem 1999; 274: 31707-31712.

86. Pennock S, Wang Z. A tale of two Cbls: interplay of c-Cbl and Cbl-b in epidermal growth factor receptor downregulation. Mol Cell Biol 2008; 28: 3020-3037.

87. Kawai M, Rosen CJ. The insulin-like growth factor system in bone: basic and clinical implications. Endocrinol Metab Clin North Am 2012; 41: 323-333; vi.

88. Mohan S, Kesavan C. Role of insulin-like growth factor-1 in the regulation of skeletal growth. Curr Osteoporos Rep 2012; 10: 178-186.

89. Marie PJ, Miraoui $\mathrm{H}$, Sévère N. FGF/FGFR signaling in bone formation: progress and perspectives. Growth Factors 2012; 30: 117-123.

90. Du X, Xie Y, Xian CJ, Chen L. Role of FGFs/FGFRs in skeletal development and bone regeneration. J Cell Physiol 2012; 227: 3731-3743.

91. Marie PJ. Fibroblast growth factor signaling controlling bone formation: an update. Gene 2012; 498: 1-4.

92. Kratchmarova I, Blagoev B, Haack-Sorensen M, Kassem M, Mann M. Mechanism of divergent growth factor effects in mesenchymal stem cell differentiation. Science 2005 308: $1472-1477$

93. Ornitz DM, Marie PJ. FGF signaling pathways in endochondral and intramembranous bone development and human genetic disease. Genes Dev 2002; 16: 1446-1465.

94. Lomri A, Lemonnier J, Hott M, de Parseval N, Lajeunie E, Munnich A et al. Increased calvaria cell differentiation and bone matrix formation induced by fibroblast growth factor receptor 2 mutations in Apert syndrome. J Clin Invest 1998; 101: 1310-1317.

95. Lemonnier J, Haÿ E, Delannoy P, Lomri A, Modrowski D, Caverzasio J et al. Role of $\mathrm{N}$-cadherin and protein kinase $\mathrm{C}$ in osteoblast gene activation induced by the $\mathrm{S} 252 \mathrm{~W}$ fibroblast growth factor receptor 2 mutation in Apert craniosynostosis. J Bone Miner Res 2001; 16: 832-845

96. Lomri A, Lemonnier J, Delannoy P, Marie PJ. Increased expression of protein kinase Calpha, interleukin-1alpha, and RhoA guanosine $5^{\prime}$-triphosphatase in osteoblasts expressing the Ser252Trp fibroblast growth factor 2 receptor Apert mutation: identification by analysis of complementary DNA microarray. J Bone Miner Res 2001; 16: 705-712.

97. Miraoui H, Oudina K, Petite H, Tanimoto Y, Moriyama K, Marie PJ. Fibroblast growth factor receptor 2 promotes osteogenic differentiation in mesenchymal cells via ERK1/2 and protein kinase C signaling. J Biol Chem 2009; 284: 4897-4904.

98. Miraoui H, Ringe J, Haupl T, Marie PJ. Increased EFG- and PDGF\{alpha\}-receptor signaling by mutant FGF-receptor 2 contributes to osteoblast dysfunction in Apert craniosynostosis. Hum Mol Genet 2010; 19: 1678-1689.

99. Miraoui $\mathrm{H}$, Marie PJ. Fibroblast growth factor receptor signaling crosstalk in skeletogenesis. Sci Signal 2010; 3: re9.

100. Andoniou CE, Lill NL, Thien CB, Lupher ML Jr., Ota S, Bowtell DD et al. The Cbl protooncogene product negatively regulates the Src-family tyrosine kinase Fyn by enhancing its degradation. Mol Cell Biol 2000; 20: 851-867.

101. Kaabeche K, Lemonnier J, Le Mée S, Caverzasio J, Marie PJ. Cbl-mediated degradation of Lyn and Fyn induced by constitutive fibroblast growth factor receptor-2 activation supports osteoblast differentiation. J Biol Chem 2004; 279: 36259-36267.

102. Ciechanover $A$. The ubiquitin-proteasome pathway: on protein death and cell life. EMBO J 1998; 17: 7151-7160.

103. Melino G. Discovery of the ubiquitin proteasome system and its involvement in apoptosis Cell Death Differ 2005: 12: 1155-1157.

104. Kaabeche K, Guénou H, Bouvard D, Didelot N, Listrat A, Marie PJ. Cbl-mediated ubiquitination of alpha5 integrin subunit mediates fibronectin-dependent osteoblast detachment and apoptosis induced by FGFR2 activation. J Cell Sci 2005; 118(Pt 6): 1223-1232.

105. Niethammer P, Delling M, Sytnyk V, Dityatev A, Fukami K, Schachner M. Cosignaling of NCAM via lipid rafts and the FGF receptor is required for neuritogenesis. J Cell Biol 2002 157: $521-532$
106. Haglund K, Ivankovic-Dikic I, Shimokawa N, Kruh GD, Dikic I. Recruitment of Pyk2 and $\mathrm{Cbl}$ to lipid rafts mediates signals important for actin reorganization in growing neurites. J Cell Sci 2004; 117(Pt 12): 2557-2568.

107. Lemonnier J, Haÿ E, Delannoy P, Fromigué O, Lomri A, Modrowski D et al. Increased osteoblast apoptosis in apert craniosynostosis: role of protein kinase $\mathrm{C}$ and interleukin-1. Am J Pathol 2001; 158: 1833-1842.

108. Dufour C, Guénou H, Kaabeche K, Bouvard D, Sanjay A, Marie PJ. FGFR2-Cbl interaction in lipid rafts triggers attenuation of PI3K/Akt signaling and osteoblast survival. Bone 2008; 42: 1032-1039.

109. Salingcarnboriboon RA, Pavasant $P$, Noda M. Cbl-b enhances Runx2 protein stability and augments osteocalcin promoter activity in osteoblastic cell lines. J Cell Physiol 2010; 224: 743-747.

110. Suzue N, Nikawa T, Onishi Y, Yamada C, Hirasaka K, Ogawa T et al. Ubiquitin ligase Cblb downregulates bone formation through suppression of IGF-I signaling in osteoblasts during denervation. J Bone Miner Res 2006; 21: 722-734.

111. Kumar EA, Charvet CD, Lokesh GL, Natarajan A. High-throughput fluorescence polarization assay to identify inhibitors of $\mathrm{Cbl}(\mathrm{TKB})$-protein tyrosine kinase interactions. Anal Biochem 2011; 411: 254-260.

112. Ciechanover A, Schwartz AL. The ubiquitin system: pathogenesis of human diseases and drug targeting. Biochim Biophys Acta 2004; 1695: 3-17.

113. Lipkowitz $\mathrm{S}$. The role of the ubiquitination-proteasome pathway in breast cancer: ubiquitin mediated degradation of growth factor receptors in the pathogenesis and treatment of cancer. Breast Cancer Res 2003; 5: 8-15.

114. Eldridge AG, O'Brien T. Therapeutic strategies within the ubiquitin proteasome system. Cell Death Differ 2010; 17: 4-13.

115. Bedford L, Lowe J, Dick LR, Mayer RJ, Brownell JE. Ubiquitin-like protein conjugation and the ubiquitin-proteasome system as drug targets. Nat Rev Drug Discov 2011; 10: $29-46$

116. Dahlmann B. Role of proteasomes in disease. BMC Biochem 2007; 8(Suppl 1): S3

117. Jones MD, Liu JC, Barthel TK, Hussain S, Lovria E, Cheng D et al. A proteasome inhibitor, bortezomib, inhibits breast cancer growth and reduces osteolysis by downregulating metastatic genes. Clin Cancer Res 2010; 16: 4978-4989.

118. Ruschak AM, Slassi M, Kay LE, Schimmer AD. Novel proteasome inhibitors to overcome bortezomib resistance. J Natl Cancer Inst 2011; 103: 1007-1017.

119. Lipkowitz S, Weissman AM. RINGs of good and evil: RING finger ubiquitin ligases at the crossroads of tumour suppression and oncogenesis. Nat Rev Cancer 2011; 11: 629-643.

120. Shi $D$, Grossman SR. Ubiquitin becomes ubiquitous in cancer: emerging roles of ubiquitin ligases and deubiquitinases in tumorigenesis and as therapeutic targets. Cancer Biol Ther 2010; 10: 737-747.

121. Huang $C$. Roles of $E 3$ ubiquitin ligases in cell adhesion and migration. Cell Adh Migr 2010; 4: $10-18$.

122. Kales SC, Ryan PE, Nau MM, Lipkowitz S. Cbl and human myeloid neoplasms: the Cbl oncogene comes of age. Cancer Res 2010; 70: 4789-4794.

123. Peschard P, Park M. Escape from Cbl-mediated downregulation: a recurrent theme for oncogenic deregulation of receptor tyrosine kinases. Cancer Cell 2003; 3: 519-523.

124. Tan $\mathrm{YH}$, Krishnaswamy S, Nandi S, Kanteti R, Vora S, Onel $\mathrm{K}$ et al. $\mathrm{CBL}$ is frequently altered in lung cancers: its relationship to mutations in MET and EGFR tyrosine kinases. PLoS One 2010; 5: e8972.

125. Kang JM, Park S, Kim SJ, Hong HY, Jeong J, Kim HS. CBL enhances breast tumor formation by inhibiting tumor suppressive activity of TGF-beta signaling. Oncogene 2012; 31: $5123-5131$

126. Lo FY, Tan YH, Cheng HC, Salgia R, Wang YC. An E3 ubiquitin ligase: c-Cbl: a new therapeutic target of lung cancer. Cancer 2011; 117: 5344-5350.

127. Marina N, Gebhardt M, Teot L, Gorlick R. Biology and therapeutic advances for pediatric osteosarcoma. Oncologist 2004; 9: 422-441.

128. Lian JB, Javed A, Zaidi SK, Lengner C, Montecino M, van Wijnen AJ et al. Regulatory controls for osteoblast growth and differentiation: role of Runx/Cbfa/AML factors. Crit Rev Eukaryot Gene Expr 2004; 14: 1-41.

129. Thomas DM, Johnson SA, Sims NA, Trivett MK, Slavin JL, Rubin BP et al. Terminal osteoblast differentiation, mediated by runx2 and p27KIP1, is disrupted in osteosarcoma. J Cell Biol 2004; 167: 925-934.

130. Martin JW, Zielenska M, Stein GS, van Wijnen AJ, Squire JA. The role of RUNX2 in osteosarcoma oncogenesis. Sarcoma 2011; 2011: 282745.

131. Pereira BP, Zhou Y, Gupta A, Leong DT, Aung KZ, Ling L et al. Runx2, p53, and pRB status as diagnostic parameters for deregulation of osteoblast growth and differentiation in a new pre-chemotherapeutic osteosarcoma cell line (OS1). J Cell Physiol 2009; 221: 778-788.

132. van der Deen M, Akech J, Lapointe D, Gupta S, Young DW, Montecino MA et al. Genomic promoter occupancy of runt-related transcription factor RUNX2 in osteosarcoma cells identifies genes involved in cell adhesion and motility. J Biol Chem 2012; 287: 4503-4517.

133. Pratap J, Lian JB, Javed A, Barnes GL, van Wijnen AJ, Stein JL et al. Regulatory roles of Runx2 in metastatic tumor and cancer cell interactions with bone. Cancer Metastasis Rev 2006; 25: 589-600.

134. Shapovalov Y, Benavidez D, Zuch D, Eliseev RA. Proteasome inhibition with bortezomib suppresses growth and induces apoptosis in osteosarcoma. Int $J$ Cancer 2010; 127: 67-76. 
135. Kubo T, Piperdi S, Rosenblum J, Antonescu CR, Chen W, Kim HS et al. Platelet-derived growth factor receptor as a prognostic marker and a therapeutic target for imatinib mesylate therapy in osteosarcoma. Cancer 2008; 112: 2119-2129.

136. Sévère $N$, Dieudonné $F X$, Marty $C$, Modrowski $D$, Patino-Garcia $A$, Lecanda $F$ et al. Targeting the E3 ubiquitin casitas B-lineage lymphoma decreases osteosarcoma cell growth and survival and reduces tumorigenesis. J Bone Miner Res 2012; 27: 2108-2117.

137. Ho AL, Schwartz GK. Targeting of insulin-like growth factor type 1 receptor in Ewing sarcoma: unfulfilled promise or a promising beginning? J Clin Oncol 2011; 29: 4581-4583.

138. Bedford L, Lowe J, Dick LR, Mayer RJ, Brownell JE. Ubiquitin-like protein conjugation and the ubiquitin-proteasome system as drug targets. Nat Rev Drug Discov 2011; 10: 29-46.
139. Marx C, Held JM, Gibson BW, Benz CC. ErbB2 trafficking and degradation associated with K48 and K63 polyubiquitination. Cancer Res 2010; 70: 3709-3717.

140. Williams SA, Maecker HL, French DM, Liu J, Gregg A, Silverstein LB et al. USP1 deubiquitinates ID proteins to preserve a mesenchymal stem cell program in osteosarcoma. Cell 2011; 146: 918-930.

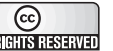

Cell Death and Disease is an open-access journal published by Nature Publishing Group. This work is licensed under the Creative Commons Attribution-NonCommercial-No Derivative Works 3.0 Unported License. To view a copy of this license, visit http://creativecommons.org/licenses/by-nc-nd/3.0/ 